\title{
Synthesis and antifungal activities of novel nicotinamide derivatives containing 1,3,4-oxadiazole
}

\author{
Jian Wu ${ }^{1,2^{*}}$, Shenghong Kang ${ }^{1,2}$, Lijun Luo ${ }^{1,2}$, Qingcai Shi ${ }^{1,2}$, Juan Ma ${ }^{1,2}$, Juan Yin ${ }^{1,2}$, Baoan Song ${ }^{1,2}$, Deyu Hu $u^{1,2}$ \\ and Song Yang ${ }^{1,2}$
}

\begin{abstract}
Background: Pant diseases in agriculture are extremely difficult to control, which bring about for billions of dollars in economic losses worldwide each year; Nicotinamide derivatives has attracted more and more attention in the field of pesticide due to their broad bioactivities. In an effort to discover new molecules with good antifungal activity, a series of nicotinamide derivatives containing 1,3,4-oxadiazole were synthesized and bio-assayed.

Results: Bioassays demonstrated that some of the title compounds exhibited favorable antifungal activities against Gibberella zeae, Fusarium oxysporum, and Cytospora mandshurica. compounds 7b, 7c, 8, 9a, 9b, and 9c displayed $46.4 \%, 39.6 \%, 53.0 \%, 43.2 \%, 58.3 \%, 45.6 \%$ activities against G. Zeae, respectively; the activities of compounds $7 \mathrm{a}, 7 \mathrm{~b}$, $8,9 \mathrm{a}, 9 \mathrm{~b}$, and $9 \mathrm{c}$ against $F$. oxysporum were $55.2 \%, 51.1 \%, 58.9 \%, 63.2 \%, 53.3 \%$, and $47.6 \%$, respectively; whereas inhibitory rates of compounds 7a, 7b, 7c, 8, 9a, 9b, and 9c on C. mandshurica were 53.1\%, 49.9\%, 44.9\%, 52.8\%, $59.8 \%, 54.5 \%$, and $49.3 \%$, respectively.

Conclusion: A series of the novel nicotinamide derivatives containing 1,3,4-oxadiazole were synthesized and bioassayed. The results of antifungal tests revealed that the synthesized nicotinamide derivatives possessed weakly to moderately antifungal activities against G. zeae, F. oxysporum, and C. mandshurica. Most of the synthesized compounds exhibited similar activities as (or higher than) these of hymexozol on their corresponding fungus, and compounds $7 \mathrm{a}, 8,9 \mathrm{a}$, and $9 \mathrm{~b}$ showed considerable prospects for further optimization. Primary structure-activity relationships revealed that the introduction of the groups of 4-chloro-6-methyl on benzene, the hydrazone group containing $\mathrm{N}, \mathrm{N}$-dimethylamino, and acetyl at $-\mathrm{NH}_{2}$ could enhance the antifungal activity.
\end{abstract}

\section{Background}

In recently years, plant diseases in agriculture are extremely difficult to control due to the continued moist weather during the crop growing season and the resistance of fungicides in the pathogen population, which bring about for billions of dollars in economic losses worldwide each year [1]. Take fusarium head blight (FHB) as example, it was caused by Gibberella zeae and was endemic in the wheat producing areas of many provinces of China, this kind of disease have caused an estimated 30 to $50 \%$ of

\footnotetext{
* Correspondence: wujian2691@126.com

${ }^{1}$ State Key Laboratory Breeding Base of Green Pesticide and Agricultural Bioengineering, Key Laboratory of Green Pesticide and Agricultural Bioengineering, Ministry of Education, Guizhou University, Guiyang, China ${ }^{2}$ Research and Development Center for Fine Chemicals, Guizhou University, Guiyang 550025, China
}

reduction and even completely failure of harvests in many wheat-producing areas [2]. Therefore, the controlling of plant pathogens (such as G. zeae) has become more and more difficult, and the development of novel fungicidal molecules for these pathogens has been attracted more and more attention.

Nicotinamide derivatives, an important class of heterocyclic derivative, has attracted more and more attention in the field of pesticide due to their fungicidal activity [3-5], insecticidal activity [6-9], herbicidal activity $[8,10]$, plant growth regulator activity [11], and bactericidal activity [12-15]. In fungicidal activity regard, some nicotinamide derivatives have been developed and commercialized, an example of such a fungicide is boscalid (Figure 1), which was discovered by BASF and registered in Britain, Germany, and Switzerland in 2004
(C) Chemistry Central

(C) 2013 Wu et al.; licensee Chemistry Central Ltd. This is an Open Access article distributed under the terms of the Creative Commons Attribution License (http://creativecommons.org/licenses/by/2.0), which permits unrestricted use, distribution, and reproduction in any medium, provided the original work is properly cited. 


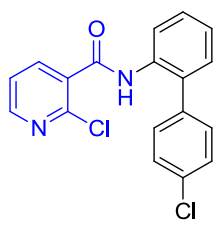

boscalid

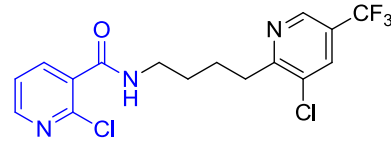

A

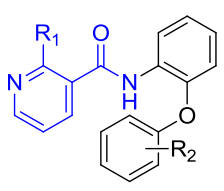

B

Figure 1 The structures of boscalid and active compounds A and B.

[16]. In 2008, Coqueron, P Y. et al. described a nicotinamide containing 4-(3-chloro-5-(trifluoromethyl) pyridin-2-yl)butyl (A, Figure 1 ) possessing good fungicidal activities against Alternaria alternate [17]. More recently, Fang W and his co-workers also reported several nicotinamide derivatives (B, Figure 1) exhibiting good fungicidal activities after modification of the boscalid structure [18].

1,3,4-oxadiazole derivatives, another important heterocyclic derivative, has attracted more and more attention in development of fungicide, in the past few years, a lots of 1,3,4-oxadiazole derivatives with good antifungal activity have been developed by our group, some of the developed compounds processed good prospects for commercialization [19-24]. New fungicidal molecules are developed in the present work on the basis of the following: incorporation of the sub-structural unit of 1,3,4-oxadiazole into the backbone of boscalid and structural variation by the introduction of different kinds of moiety, resulting in nicotinamides containing a 1,3,4-oxadiazole substructure with broad-spectrum activity. Based on this hypothesis, a series of novel nicotinamide derivatives containing 1,3,4-oxadiazole substructure were designed and synthesized. Biological assays revealed that most of the synthesized compounds were provided with weak to moderate activities against G. Zeae, F. oxysporum, and $C$. mandshurica at $50 \mathrm{mg} / \mathrm{L}$. Some of the synthesized compounds exhibited similar or higher activities as that of hymexozol on their corresponding fungus, compounds 9a, 7a, 8, and $9 \mathbf{b}$ showed considerable prospects.

\section{Results and discussion}

\section{Synthesis}

The synthetic protocol of the nicotinamide derivatives containing 1,3,4-oxadiazole are depicted in Scheme 1. Firstly, substituted-2-(2-chloropyridin-3-yl)-4H-benzo $[d]$ $[1,3]$ oxazin-4-one (3a-3d) can be synthesized by cyclisation of 2-(2-chloronicotinamido)benzoic acid (10a-10d) in refluxing acetic anhydride about $30 \mathrm{~min}$ (Scheme 2) with excellent yield (>90\%) [25-27]. However, the synthetic method showed in Scheme 2 had several shortcomings, which included long steps, poor stability of 2-chloronicotinoyl chloride, low yields and long reaction times for preparation of $10 \mathrm{a}$ to $10 \mathrm{~d}$. A single-step alternative protocol with a short reaction time and high yields (>90\%) carried out at room temperature in acetonitrile was thus employed by treatment of 2chloronicotinic acid (1) with 2-amino-sbustitutedbenzoic acid (2a-2d) in the presence of pyridine and methanesulfonyl chloride $[14,25,28,29]$. The further reaction of substituted-2-(2-chloropyridin-3-yl)-4H-benzo[ $d]$ [1,3] oxazin-4-one (3a-3d) with $80 \%$ hydrazine hydrate could carry out readily in $1 \mathrm{~h}$ at room temperature to give substituted- $N$-(2-(hydrazinecarbonyl) phenyl) nicotinamide (4a-4d) [14]. Subsequent treatment of intermediates $4 \mathbf{d}$ with $\mathrm{CS}_{2}$ in present of $\mathrm{KOH}$ in refluxing ethanol afforded 2-chloro- $N$-(2-(5-mercapto-1,3,4oxadiazol-2-yl)phenyl)nicotinamide (5), which further reacted with $\mathrm{Me}_{2} \mathrm{SO}_{4}$ in present of $\mathrm{KOH}$ in water to give 2-chloro- $N$-(2-(5-(methylthio)-1,3,4-oxadiazol-2-yl) phenyl)nicotinamide (6). Moreover, $N$-(2-(5-amino-1,3,4oxadiazol-2-yl)-substituted-phenyl)-2-chloronicotinamide $7 \mathbf{a}-7 \mathbf{d}$ can be prepared by treatment of $4 \mathbf{a}-4 \mathbf{d}$ with $\mathrm{BrCN}$ in present of $\mathrm{KHCO}_{3}$ in dry tetrahydrofuran (THF), receptivity [30], compound $\mathbf{8}$ then can be obtained by using compound $\mathbf{7 b}$ in refluxing acetic anhydride for 30 min with $85 \%$ yield. Finally, 9a, 9b, 9c, and 9d were conveniently obtained with $>90 \%$ yields by treatment of $7 \mathbf{a}, 7 \mathbf{b}, 7 \mathbf{c}$, and, $7 \mathbf{d}$ with 2,2-dimethoxy- $N, N$ dimethylethenamine about 15 min in refluxing $\mathrm{EtOH}$, respectively. The procedure for preparation of the intermediates and title compounds can be found in Additional file 1.

The structures of the synthesized compounds (5-9) were established on the basis of their spectroscopic data. The IR spectra showed absorption bands around near $3230-3400 \mathrm{~cm}^{-1}, 2990-3150 \mathrm{~cm}^{-1}$ for the N-H, and Ar-H stretching vibrations, respectively. The absorption bands near $1670-1710 \mathrm{~cm}^{-1}$ were the presence $\mathrm{C}=\mathrm{O}$ functional groups, the absorption bands of $1450-1620 \mathrm{~cm}^{-1}$ were the skeletal vibration of benzene ring. In the ${ }^{1} \mathrm{H}-\mathrm{NMR}$ spectra of the title compounds, the -CONHAr proton appeared as a broad singlet at 11.88-10.27 ppm range; the $-\mathrm{CH}=\mathrm{N}$ - proton for compounds 9a-9d mainly appeared as a singlet near the $8.50 \mathrm{ppm}$; the protons at 6 and 4 positions of pyridine ring were occurred as double-double peaks near 8.57-8.51 and 7.61-8.33, respectively; and the protons at 5 position of pyridine is 


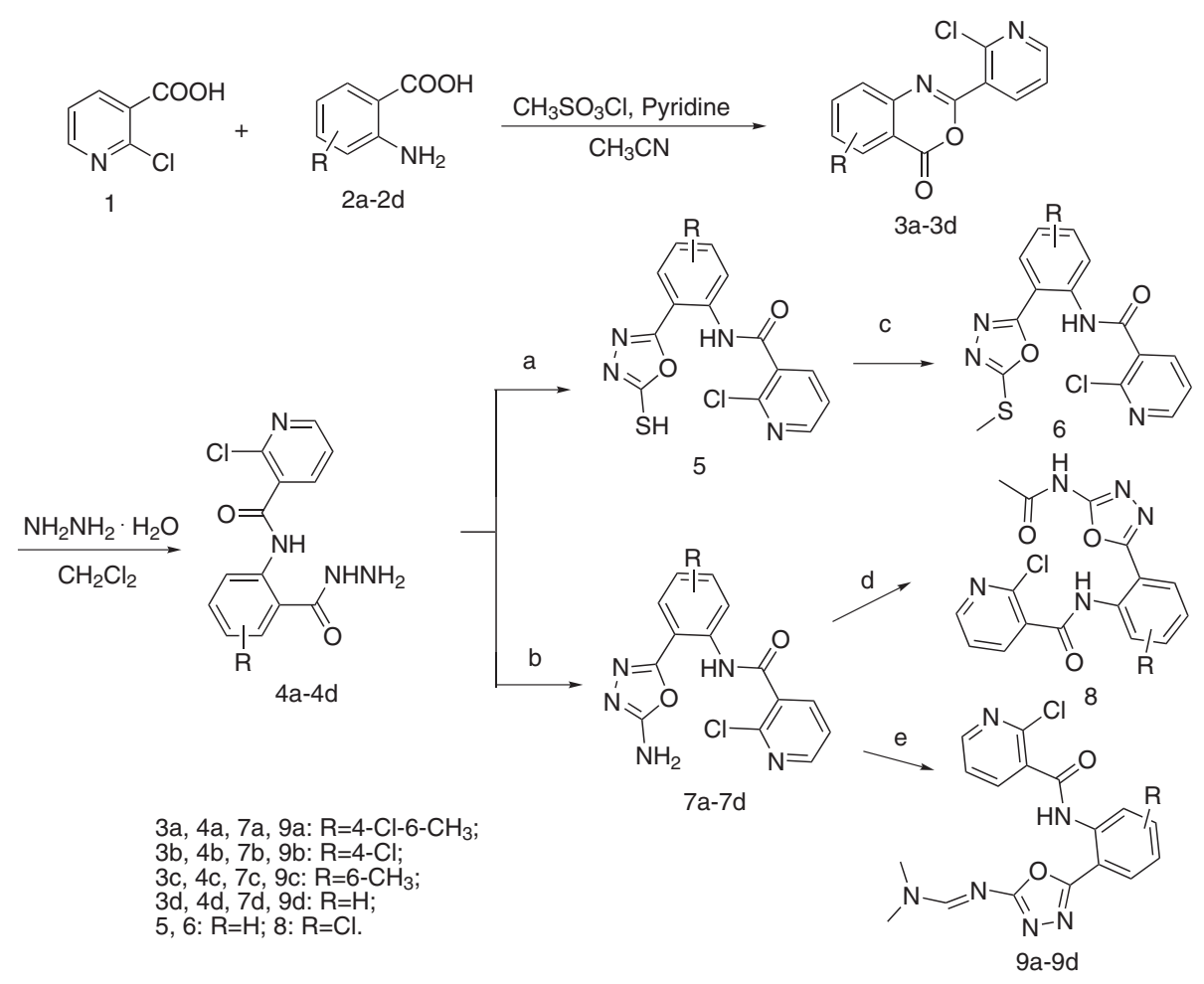

Scheme 1 Synthetic route to nicotinamide derivatives containing 1,3,4-oxadiazole. Reagents and conditions: (a). $\mathrm{KOH}, \mathrm{EtOH}, \mathrm{CS}_{2}, \mathrm{reflux}$; (b). $\mathrm{BrCN}, \mathrm{KHCO}_{3}, \mathrm{THF}, \mathrm{rt} ;$ (c). $\mathrm{KOH}, \mathrm{Me}_{2} \mathrm{SO}_{4}, \mathrm{H}_{2} \mathrm{O}$. (d). (AcO) $)_{2} \mathrm{O}$, reflux; (e). 2,2-dimethoxy-N,N-dimethylethenamine, EtOH, reflux.

near the $7.60 \mathrm{ppm}$. The properties, ${ }^{1} \mathrm{H}$ NMR, ${ }^{13} \mathrm{C}$ NMR, IR, and the elemental analysis data of the title compounds in more detail are also listed in Additional file 1 [see Additional file 1].

\section{Antifungal activity and structure activity relationship}

The antifungal activities of compounds 5-9 against $G$. Zeae, F. oxysporum, and C. mandshurica were assayed using the poison plate technique [31,32]. Hymexazol and carbendazol were used as positive control. The results listed in Table 1 indicated that most of the synthesized compounds were provided with weak to moderate activities against G. Zeae, F. oxysporum, and C. mandshurica at $50 \mathrm{mg} / \mathrm{L}$. It can be seen that compounds $7 \mathbf{b}, 7 \mathbf{c}, \mathbf{8}, \mathbf{9 a}$, 9b, and 9c displayed 46.4\%, 39.6\%, 53.0\%, 43.2\%, 58.3\%, $45.6 \%$ activities against G. Zeae, respectively; the activties of compounds $7 \mathbf{a}, 7 \mathbf{b}, \mathbf{8}, \mathbf{9 a}, \mathbf{9 b}$, and $9 \mathbf{c}$ against $F$. oxysporum were $55.2 \%, 51.1 \%, 58.9 \%, 63.2 \%, 53.3 \%$, and $47.6 \%$, respectively; whereas inhibitory rates of compounds $7 \mathbf{a}, 7 \mathbf{b}, 7 \mathbf{c}, \mathbf{8}, \mathbf{9 a}, \mathbf{9 b}$, and $9 \mathbf{c}$ on $C$. mandshurica were $53.1 \%, 49.9 \%, 44.9 \%, 52.8 \%$, 59.8\%, $54.5 \%$, and $49.3 \%$, respectively. It can concluted from these active data that these compounds exhibited similar activities as (or higher than) these of hymexozol on their corresponding fungus, and the compounds 9a (against both F. oxysporum and C. mandshurica), 7a, 8, and $\mathbf{9 b}$ (against C. mandshurica) showed considerable prospects.

Primary structure activity relationships (SAR) revealed that antifungal activities on the three fungus can be improved to a certain extent by introduction of $N, N$ dimethylamino. For instance, compound 9a showed much higher activities against both G. Zeae and $F$.

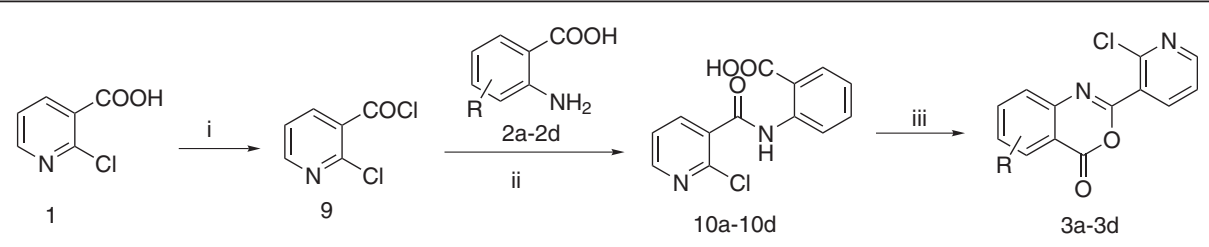

Scheme 2 Synthetic route to intermediates 3a-9c. Reagents and conditions: (i). $\mathrm{Cl}_{2} \mathrm{SO}$, reflux, 2 h; (ii). $\mathrm{Et}_{3} \mathrm{~N}_{,} \mathrm{CH}_{3} \mathrm{Cl}$, reflux, $<70 \%$; (iii). ( $\left.\mathrm{AcO}\right)_{2} \mathrm{O}$, reflux, 30 min. 


\begin{tabular}{|c|c|c|c|}
\hline \multirow[t]{2}{*}{ Compound } & \multicolumn{3}{|c|}{ Inhibition rate ${ }^{a}(\%)$} \\
\hline & G. zeae & F. oxysporum & C.mandshurica \\
\hline 5 & $17.9 \pm 1.6$ & $10.3 \pm 0.9$ & $15.5 \pm 0.7$ \\
\hline 6 & $33.2 \pm 1.7$ & $21.3 \pm 1.1$ & $30.3 \pm 1.9$ \\
\hline $7 a$ & $19.0 \pm 2.9$ & $55.2 \pm 0.6$ & $53.1 \pm 1.3$ \\
\hline $7 b$ & $46.4 \pm 1.3$ & $51.1 \pm 1.0$ & $49.9 \pm 1.1$ \\
\hline $7 c$ & $39.6 \pm 1.3$ & $31.9 \pm 1.4$ & $44.9 \pm 0.7$ \\
\hline $7 d$ & $27.9 \pm 0.2$ & $12.5 \pm 1.7$ & $17.3 \pm 1.0$ \\
\hline 8 & $53.0 \pm 2.4$ & $58.9 \pm 4.3$ & $52.8 \pm 1.3$ \\
\hline $9 a$ & $43.2 \pm 0.6$ & $63.2 \pm 0.9$ & $59.8 \pm 1.4$ \\
\hline $9 b$ & $58.3 \pm 2.7$ & $53.3 \pm 3.9$ & $54.5 \pm 1.2$ \\
\hline $9 c$ & $45.6 \pm 1.8$ & $47.6 \pm 1.0$ & $49.3 \pm 1.1$ \\
\hline $9 d$ & $35.4 \pm 1.9$ & $17.2 \pm 0.3$ & $34.3 \pm 0.9$ \\
\hline Hymexazol $^{b}$ & $55.54 \pm 3.9$ & $56.12 \pm 2.1$ & $49.61 \pm 3.2$ \\
\hline Carbendazol $^{\mathrm{b}}$ & $100 \pm 3.74$ & $100 \pm 4.9$ & $100 \pm 5.23$ \\
\hline
\end{tabular}

${ }^{a}$ Average of three replicates, ${ }^{\mathrm{b}}$ The commercial agricultural fungicide hymexazol and carbendazol were used for activity comparison.

oxysporum than that of $7 \mathbf{a}$, and compounds $\mathbf{9 b - 9 d}$ also showed slightly better activities than these of $\mathbf{7 b}-\mathbf{7} \mathbf{d}$. In addition, the introduction of acetyl can enhance the antifungal activity when chlorine was at 4-position of benzene, that why compound $\mathbf{8}$ showed higher activity than that of compound $\mathbf{7 b}$. Moreover, the substituent on benzene play an important role when the group on 1,3,4-oxadiazole was "- $\mathrm{NH}_{2}$ ", as we can see that compound 7a $(\mathrm{R}=4$-chloro-6-methyl) showed higher activity than that of $\mathbf{7 b}(\mathrm{R}=4$-chloro), and compound $\mathbf{7 c}$ ( $\mathrm{R}=6$-methyl) showed slightly lower activity, and the activity of $7 \mathbf{d}(\mathrm{R}=\mathrm{H})$ was the lowest one. So the active order was $7 \mathbf{a}>7 \mathbf{b}>7 \mathbf{c}>7 \mathbf{d}$; a similar case can be found when $-\mathrm{NH}_{2}$ group was changed to $-\mathrm{N}=\mathrm{CHN}\left(\mathrm{CH}_{3}\right)_{2}$ $(9 a>9 b>9 c>9 d)$. Finally, the compound with thiol (5) displayed much lower activity than that of the compound with amino group, but the introduction of $-\mathrm{CH}_{3}$ group (compound 6) could increase the activity against all the test fungus. Further structural modification is currently underway basing on the primary SAR to discover the potential nicotinamides containing 1,3,4-oxadiazole.

\section{Experimental \\ Chemistry}

Unless otherwise stated, all the reagents and reactants were purchased from commercial suppliers; melting points were uncorrected and determined on a XT-4 binocular microscope (Beijing Tech Instrument Co., China). The ${ }^{1} \mathrm{H}$-NMR and ${ }^{13} \mathrm{C}$-NMR spectra were recorded on a JEOL ECX 500 NMR spectrometer (JEOL Ltd., Japan) at room temperature operating at $500 \mathrm{MHz}$ for ${ }^{1} \mathrm{H}$-NMR and $125 \mathrm{MHz}$ for ${ }^{13} \mathrm{C}$-NMR by using
$\mathrm{CDCl}_{3}$ or DMSO as solvents and TMS as an internal standard; infrared spectra were recorded in $\mathrm{KBr}$ on a IR Pristige-21 spectrometer (Shimadzu corporation, Japan); elemental analysis was performed on an Elemental Vario-III CHN analyzer (Elementar, German). The course of the reactions was monitored by TLC; analytical TLC was performed on silica gel GF 254. Intermediates 3 and $\mathbf{4}$ were prepared according to the reported methods [14] and used without further purifications, the process for preparing of them can be found in Additional file 1.

\section{Antifungal biological assay}

All the compounds $(\mathbf{5}, \mathbf{6}, \mathbf{7 a - 7 d}, \mathbf{8}, \mathbf{9 a - 9 d})$ were evaluated for their antifungal activities against G. zeae, F. oxysporium, and C. mandshurica in vitro as described in literature $[31,32]$. The results of preliminary bioassays were compared with the experimental data of the commercial agricultural fungicide, hymexazol and carbendazim. All the compounds were dissolved in dimethyl sulfoxide (DMSO, $10 \mathrm{~mL}$ ) before mixing with potato dextrose agar (PDA, $90 \mathrm{~mL}$ ). The compounds were tested at a concentration of $50 \mathrm{mg} / \mathrm{L}$. All fungal species were incubated in PDA at $27 \pm 1^{\circ} \mathrm{C}$ for 5 days to obtain new mycelium for antifungal assay. Mycelia dishes approximately $4 \mathrm{~mm}$ in diameter were cut from the culture medium. One of the specimens was picked up with a sterilized inoculation needle and then inoculated in the center of the PDA plate aseptically. The inoculated plates were incubated at $27 \pm 1^{\circ} \mathrm{C}$ for 5 days. DMSO in sterile distilled water served as the control, whereas hymexazol and carbendazim acted as the positive control. Three replicates were conducted for each treatment. The radial growth of the fungal colonies was measured on the sixth day and the data were statistically analyzed. The in vitro inhibiting effects of the test compounds on the fungi were calculated by the formula:

$\mathrm{I}(\%)=[(\mathrm{C}-\mathrm{T}) /(\mathrm{C}-0.4)] \times 100$, where $\mathrm{C}$ represents the diameter of fungal growth on untreated PDA, $\mathrm{T}$ represents the diameter of fungi on treated PDA, and I is the inhibitory rate.

\section{Conclusion}

In conclusion, a series of the novel nicotinamide derivatives containing 1,3,4-oxadiazole were designed and synthesized. The synthesized compounds were characterized by spectral data $\left({ }^{1} \mathrm{H}\right.$ NMR, ${ }^{13} \mathrm{C}$ NMR, IR) and elemental analysis. All of the compounds were subjected to fungicidal activities in vitro against G. zeae, F. oxysporum, and C. mandshurica. The results showed that the synthesized nicotinamide derivatives possessed weakly to moderately antifungal activities against the tested fungus. Most of the synthesized compounds exhibited similar activities as (or higher activities than) that of hymexozol on their corresponding 
fungus, and the compounds $9 \mathbf{a}, 7 \mathbf{a}, \mathbf{8}$, and $\mathbf{9 b}$ showed considerable prospects for further optimization. Primary structure activity relationships revealed that the introduction of the groups of 4-chloro-6-methyl on benzene, the hydrazone group containing $\mathrm{N}, \mathrm{N}$-dimethylamino, and acetyl at $-\mathrm{NH}_{2}$ could enhance the antifungal activities against G. zeae, F. oxysporum, and C. mandshurica. However, the structures of the synthesized compounds need to be optimized. Further structural modification and biological evaluation are currently underway to explore the full potential of this kind of nicotinamides containing 1,3,4-oxadiazole.

\section{Additional file}

Additional file 1: Experimental details and spectroscopic data of the intermediates 3-4 and the title compounds 5-9. Which includes the experimental procedure and the ${ }^{1} \mathrm{H}$ NMR of intermediates (3a-3d and $\mathbf{4 a - 4 d )}$ ), the experimental protocols and the spectroscopic data of title compounds $\mathbf{5}, \mathbf{6}, \mathbf{7 a}-\mathbf{7 a}, \mathbf{8}$, and $\mathbf{9 a}-\mathbf{9 d}$. All the copies of ${ }^{1} \mathrm{H}$ NMR and ${ }^{13} \mathrm{C}$ NMR for the title compounds were also presented in this additional file.

\section{Competing interests}

The authors declare that they have no competing interests.

\section{Authors' contributions}

The current study is an outcome of constructive discussion with BAS, SY and $\mathrm{DYH} ; \mathrm{JW}$ carry out their synthesis and characterization experiments was also involved in the drafting of the manuscript. JY performed the antifungal activities; JM and QC Shi carried out the ${ }^{1} \mathrm{H}$ NMR, ${ }^{13} \mathrm{C}$ NMR spectral analyses; SHK and LJL carried out the elemental analysis and infrared spectroscopy. JW and SY were involved in revising the manuscript. All authors read and approved the final manuscript.

\section{Acknowledgements}

This work was supported Key Technologies R\&D Program (No.2011BAE06B056) and the Special Foundation of Governor for Outstanding talents in Guizhou (No.2011-38) the Introduction of Talent Research projects of Guizhou University (No. 2011-24).

Received: 11 February 2013 Accepted: 21 March 2013

Published: 5 April 2013

\section{References}

1. Bai GH, Gregory S: Management and resistance in wheat and barley to fusarium head blight. Annu Rev Phytopathol 2004, 42:135-161.

2. De Wolf ED, Madden LV, Lipps PE: Risk assessment models for wheat Fusarium head blight epidemics based on within-season weather data. Phytopathol 2003, 93:428-435.

3. Komori T, Ujita S, Inoue T: Preparation of $N$-(3-phenoxybenzyl) nicotinamide derivatives as plant fungicides. Chem Abstr 2010, 154:64642.

4. Kozlevcar B, Leban I, Turel I, Segedin P, Petric M, Pohleven F, White Andrew JP, Williams DJ, Sieler J: Complexes of copper(II) acetate with nicotinamide: preparation, characterization and fungicidal activity; crystal structures of $\left[\mathrm{Cu}_{2}\left(\mathrm{O}_{2} \mathrm{CCH}_{3}\right)_{4}(\mathrm{nia})\right]$ and $\left[\mathrm{Cu}_{2}\left(\mathrm{O}_{2} \mathrm{CCH}_{3}\right)_{4}\left(\mathrm{nia}_{2}\right]\right.$. Polyhedron 1999, 18:755-762.

5. Komori T, Ujita S, Inoue T: Preparation of N-(4-phenoxybenzyl)pyridine-3carboxamide derivatives as plant fungicides. Chem Abstr 2010, 154:64641.

6. Frackenpohl J, Hense A, Arnold C, Franken EM, Malsam O, Sanwald E, Goergens U: Preparation of Nicotinamides as Agrochemical Insecticides. Chem Abstr 2008, 152:287405.

7. Yokoi S, Obayashi T, Sato K, Nagai J, Kawagishi A, Mtsuo S: Pest control compositions containing $\mathrm{N}$-heteroaryl-nicotinamides and insecticides, acaricides, or nematocides. Chem Abstr 2005, 142:256292.
8. Zhu YC, Yuan LP, Cao J, Shen XX, Lu DH, Ni CC, Shen Z, Chen L, Zhang YB: Synthesis and bioactivity of 2-benzylsulfanyl nicotinamide derivatives. Agrichemicals 2008, 10:287-291.

9. Gesing ERF, Mueller KH, Kysela E, Drewes MW, Dahmen P, Feucht D, Pontzen R: Preparation of $\mathrm{N}$-phenylnicotinamides for use as herbicides. Chem Abstr 2001, 134:266207.

10. Jeschke P, Lindner W, Bonse G, Santel HJ, Luerssen K, Schmidt RR, Hartwig J: Herbicidal and plant-mematocidal compositions based on mercaptonicotinic acid derivatives. Chem Abstr 1993, 119:160137.

11. Chung IM, Kim JJ, Chun SC, Ahmad A: Potential herbicidals and growth regulators constituents in rice hulls of oryza sativa. J Chem 2008, 20:820-822.

12. Thomas AB, Nanda RK, Kothapalli LP, Deshpande AD: Synthesis and antimicrobial activity of $N$-[2-(aryl/substituted aryl)-4-oxo-1,3thiazolidin- 3-yl]pyridine-4-carboxamide. J Kor Chem Soc 2011, 55:960-968

13. Vijay $\mathrm{V}$, Soni $\mathrm{N}$, Khanna $\mathrm{V}$ : Synthesis and antimicrobial activity of 5 -arylidine derivatives of $\mathrm{N}$-(2-(4-chlorophenyl)-4-oxo-3-thiazolidinyl)isonicotinamide. Inter J Res Pharm Sci 2011, 1:34-43.

14. Wu J, Kang SH, Song BA, Hu DY, He M, Jin LH, Song Y: Synthesis and antibacterial activity against ralstonia solanacearum for novel hydrazone derivatives containing a pyridine moiety. Chem Cent J 2012, 6:28.

15. Dhore JW, Pethe GB, Wagh SP, Thorat GD: Synthesis, characterization and biological studies of some triazolyl isonicotinamide. Arch App/ Sci Res 2011, 3:407-414.

16. Liu CL: World Pesticides: Fungicide. Beijing: Chemical Industry Press; 2006.

17. Queron PY, Grosjean-Cournoyer MC, Desbordes P, Genix P, Hartmann B, Mattes A, Kunz K, Fischer R, Gaertzen O, Ort O, Mansfield D, Villier A: N-[4-(pyridin-2-yl) butyl]-carboxamide derivatives as fungicides, their preparation, fungicidal compositions, and use for the control of phytopathogenic fungi. Chem Abstr 2008, 148:121597.

18. Wen F, Zhang H, Yu ZY, Jin H, Yang Q, Hou TP: Design, synthesis and antifungal/insecticidal evaluation of novel nicotinamide derivatives. Pestic Biochem Phy 2010, 98:248-253.

19. Xu WM, Yang S, Bhadury P, He J, He M, Gao LL, Hu DY, Song BA: Synthesis and bioactivity of novel sulfone derivatives containing 2,4dichlorophenyl substituted 1,3,4-oxadiazole/thiadiazole moiety as chitinase inhibitors. Pestic Biochem Phy 2011, 101:6-15.

20. Jin LH, He J, He M, Xu WM, Yang S: The preliminary study of inhibitory mechanism of sulfone compounds xa202 and xt208 against Gibberella zeae. Afr J Micr Res 2011, 5:4889-4895.

21. Xu WM, He J, He M, Han FF, Chen XH, Pan ZX, Wang J, Tong MG: Synthesis and antifungal activity of novel sulfone derivatives containing 1,3,4-oxadiazole moieties. Molecules 2011, 16:9129-9141.

22. Xu WM, Han FF, He M, Hu DY, He J, Yang S, Song BA: Inhibition of tobacco bacterial wilt with sulfone derivatives containing an 1,3,4-oxadiazole moiety. J Agric Food Chem 2012, 60:1036-1041.

23. Chen CJ, Song BA, Yang S, Xu GF, Bhadury PS, Jin LH, Hu DY, Li QZ, Liu F, Xue W, Chen Z: Synthesis and antifungal activities of 5-(3,4,5-trimethoxyphenyl)2-sulfonyl-1,3,4-thiadiazole and 5-(3,4,5-trimeth -oxyphenyl)-2-sulfonyl1,3,4-oxadiazole derivatives. Bioorg Med Chem 2007. 15:3981-3989.

24. Liu F, Luo XQ, Song BA, Bhadury PS, Yang S, Jin LH, Xue W, Hu DY: Synthesis and antifungal activity of novel sulfoxide derivatives containing trimethoxyphenyl substituted 1,3,4-thiadiazole and 1,3,4-oxadiazole moiety. Bioorg Med Chem 2008, 16:3632-3640.

25. Wu J, Song BA, Hu DY, Yue M, Yang S: Design, synthesis and insecticidal activities of novel pyrazole amides containing hydrazone substructures. Pest Manag Sci 2012, 68:801-810.

26. Wright SW, Petraitis JJ, Abelman MM, Batt DG, Bostrom LL, Corbett RL, Decicco CP, Di Meo SV, Freimark B, Giannaras JV, Green AM, Jetter JW, Nelson DJ, Orwat MJ, Pinto DJ, Pratta MA, Sherk SR, Williams JM, Magolda RL, Aner EC: Heteroaryl-fused 2-phenylisothiazolone inhibitors of cartilage breakdown. J Med Chem 1994, 37:3071-3078.

27. Pommer EH, Zeeh B, Goetz N, Girgensohn B: Fungicidal compositions containing pyridine carboxylic acid derivatives. Chem Abstr 1976, 84:39707.

28. Clark DA, Lahm GP, Smith BK, Barry JD, Clagg DG: Synthesis of insecticidal fluorinated anthranilic diamides. Bioorg Med Chem 2008, 16:3163-3170.

29. Rose U: 2-Aryl-substituted 4H-3,1-benzoxazin-4-ones as novel active substances for the cardiovascular system. J Heterocyclic Chem 1991, 28:2005-2012. 
30. Fallon GD, Francis $C L$, Johansson $\mathrm{K}$, Liepa AJ, Woodgate RCJ: N, N-Dialkyl$\mathrm{NI}$-Chlorosulfonylchloroformamidines in Heterocyclic Synthesis. II. Thiazolo-, Thiadiazolo-, and Oxadiazolo- Fused $[1,2,4,6]$ Thiatriazine Dioxides. Austr J Chem 2005, 58:891-900.

31. Wu J, Wang J, Hu DY, He M, Jin LH, Song BA: Synthesis and antifungal activity of novel pyrazolecarboxamide derivatives containing a hydrazone moiety. Chem Cent J 2012, 6:51.

32. Song $S Q$, Zhou LG, Li D, Tang D, Li JQ, Jiang WB: Antifungal activity of five plants from Xinjiang. Nat Prod Res Dev 2004, 16:157-159.

doi:10.1186/1752-153X-7-64

Cite this article as: Wu et al: Synthesis and antifungal activities of novel nicotinamide derivatives containing 1,3,4-oxadiazole. Chemistry Central Journal 2013 7:64.

\section{Publish with ChemistryCentral and every scientist can read your work free of charge \\ "Open access provides opportunities to our colleagues in other parts of the globe, by allowing anyone to view the content free of charge." \\ W. Jeffery Hurst, The Hershey Company. \\ - available free of charge to the entire scientific community \\ - peer reviewed and published immediately upon acceptance \\ - cited in PubMed and archived on PubMed Central \\ - yours - you keep the copyright \\ Submit your manuscript here: \\ http://www.chemistrycentral.com/manuscript/<smiles>c1ccccc1</smiles> 